\title{
Cor triatriatum sinister: Is it less sinister in older patients?
}

\author{
Phillip S. Naimo, MD, and Igor E. Konstantinov, MD, PhD, FRACS
}

\footnotetext{
From Cardiothoracic Surgery, Royal Children's Hospital; Murdoch Children's Research Institute; and University of Melbourne, Melbourne, Australia.

Disclosures: Authors have nothing to disclose with regard to commercial support.

Received for publication Aug 9, 2015; revisions received Aug 9, 2015; accepted for publication Aug 10, 2015; available ahead of print Sept 11, 2015

Address for reprints: Igor E. Konstantinov, MD, PhD, FRACS, Cardiothoracic Surgery, Royal Children's Hospital, University of Melbourne, Flemington Rd, Parkville, Victoria 3029, Australia (E-mail: igor.konstantinov@ rch.org.au).

J Thorac Cardiovasc Surg 2015;150:e77-8

$0022-5223 / \$ 36.00$

Crown Copyright $@ 2015$ Published by Elsevier Inc. on behalf of The American Association for Thoracic Surgery http://dx.doi.org/10.1016/j.jtcvs.2015.08.030
}

In a brief article in the current issue of the Journal, Said and colleagues $^{1}$ describe a teenager with persistent hemoptysis. The patient underwent extensive evaluation, including bronchoscopy and computed tomography, to rule out infectious or hematologic causes of the hemoptysis. Referral to a tertiary hospital was made for further management of hypersensitivity pneumonitis and pulmonary fibrosis. This patient had a surprisingly sinister history until echocardiogram demonstrated a cor triatriatum sinister (CTS). The surgical management was then straightforward and simple. The article emphasizes the fact that hemoptysis can be of cardiac origin, particularly in those with pulmonary venous drainage obstruction. A simple auscultation of the heart should not be scorned when examining any patient with persistent hemoptysis.

CTS is indeed a very rare anomaly, and it is even rarer in older patients. CTS can occur in isolation (classic) or in association with other congenital cardiac anomalies (atypical). The atypical form occurs in $50 \%$ to $85 \%$ of all patients with $\mathrm{CTS},{ }^{2-4}$ although it is rare in adolescents and adults. Older patients more often have an isolated type of CTS.

A previously published article from our institution described 28 patients with CTS seen from 1981 to 2003. Seven patients $(25 \%)$ were neonates and 8 patients $(29 \%)$ were infants. Most patients $(86 \% ; 24 / 28)$ were seen by 5 years of age, and all but 1 patient had been seen by 10 years of age. To date, of 42 patients with CTS operated on from 1981 to 2015 at the Royal Children's Hospital in Melbourne, only 4 patients were older than 10 years. Although this pattern may vary slightly according to the era of diagnosis and the referral pattern, ${ }^{2,4}$ the finding of CTS in older patients is uncommon. Typically, older patients with CTS do not have obstruction and thus may remain free of symptoms until later in life. Nonetheless, elderly patients with CTS have been described. ${ }^{5,6}$ If patients do not have restriction of blood flow through the membrane, their disease may be evidenced later in life as the fibrosis or calcification of the membrane progresses, causing obstruction of pulmonary venous blood flow. ${ }^{5-8}$

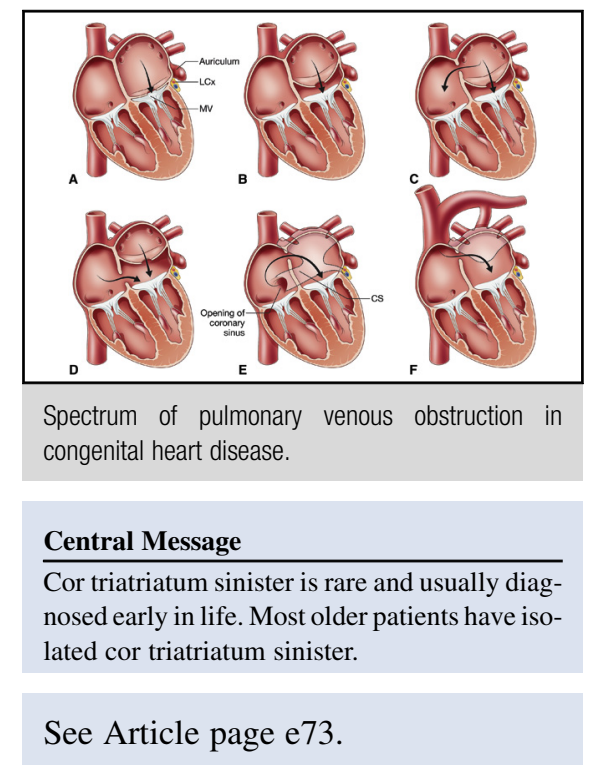

As a result, older patients may first be seen with new-onset atrial fibrillation, syncope, shortness of breath, and orthopnea. ${ }^{5-8}$

Apart from mitral stenosis, a spectrum of congenital anomalies may result in pulmonary venous blood flow obstruction and have similar clinical presentations. A supramitral membrane (Figure 1, $A$ ) is distinguished from the membrane in CTS by its location below the left atrial appendage. This is an important differentiation, because as a result of its proximity to the mitral valve and left circumflex coronary artery, the resection of a supramitral membrane is more difficult than the resection of a simple CTS membrane. ${ }^{9,10}$ A supramitral membrane is often adherent to the mitral valve leaflets. The obstruction of CTS may occur at the membrane orifice (Figure $1, B$ ) as in Lam type $\mathrm{A}^{11}$ or as in type $\mathrm{A} 1$, also at the atrial septal defect (Figure 1, C). In patients with CTS type A2, the obstructing membrane is located above the atrial septal defect, and these patients may be seen with severe hypoxia as a result of the combination of pulmonary venous obstruction and intermittent right-to-left shunting (Figure 1, D). CTS draining into the coronary sinus, Lam type B (Figure 1, $E$ ) is a misnomer and, in fact, is not different from the intracardiac type of the total anomalous pulmonary venous drainage, unless there is a separate communication of the pulmonary venous confluence with the left atrium. Obstruction in patients with total anomalous pulmonary venous drainage (Figure $1, E$ and $F$ ) occurs at the atrial septal defect or the emissary vein. 

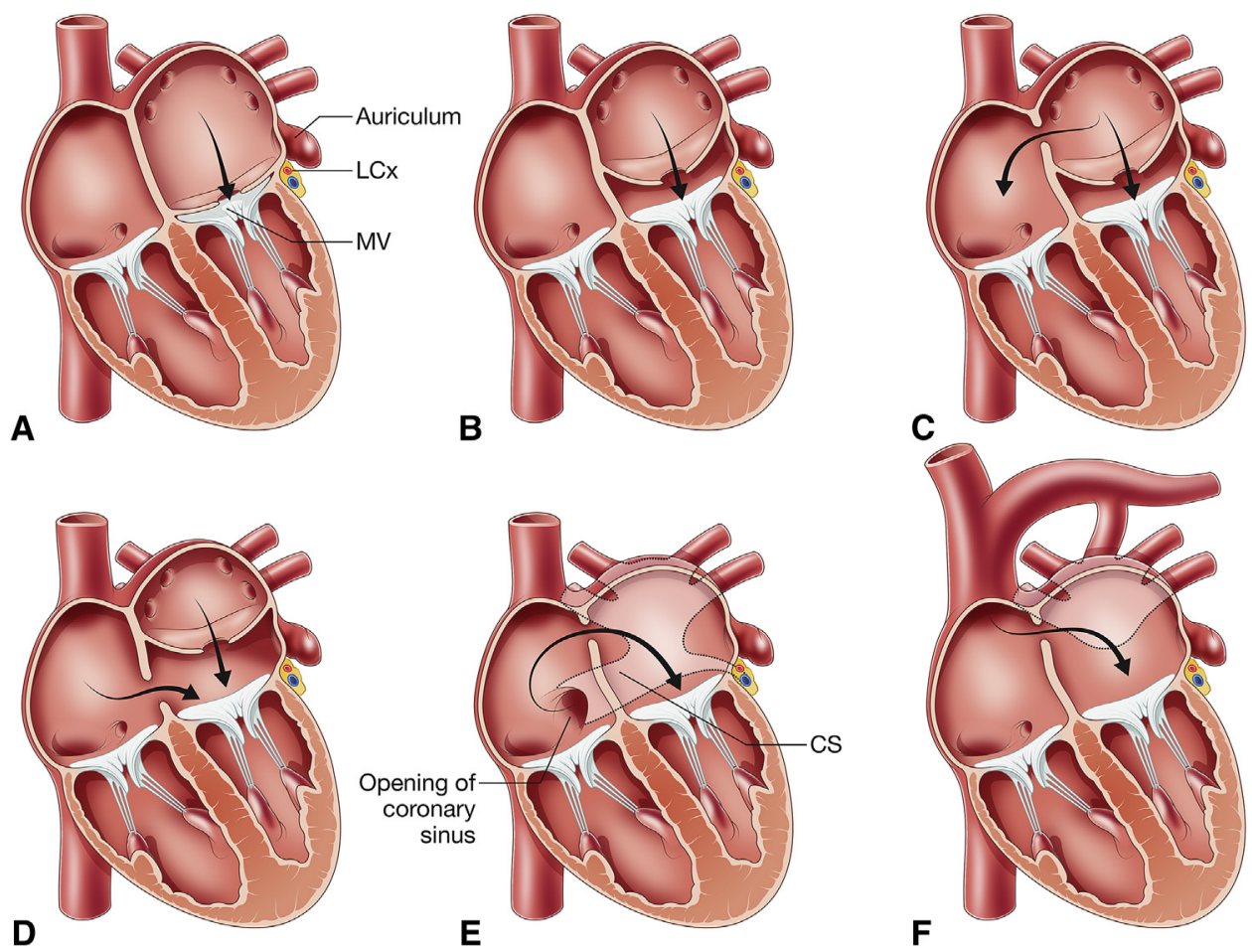

FIGURE 1. Spectrum of congenital supramitral obstruction of the pulmonary venous blood flow. A, A supramitral membrane (arrow) is located below the left atrial appendage (Auriculum), attached to the base of the mitral valve $(M V)$ and in close proximity to the left circumflex coronary artery $(L C x)$. B, C, and $\mathrm{D}$, The pulmonary venous confluence in cor triatriatum sinister is separated from the mitral valve by a membrane located above the left atrial appendage (arrow) and may have an associated atrial septal defect (curved arrow in C and D runs through the defect). E and F, Pulmonary confluence in total anomalous pulmonary venous drainage (arrow) does not have a direct connection to the left atrium but instead occurs through the emissary vein into the coronary sinus $(C S$ in $\mathrm{E})$, superior vena cava $(\mathrm{F})$, or inferior vena cava and can be obstructed at the level of the atrial septal defect.

Surgery in patients with CTS is performed with good outcomes. Mortality and reoperation rate are nearly $0 \%$ in patients with classic CTS and are determined by the repair of associated anomalies in atypical CTS. Because of natural selection, congenital cardiac anomalies that present in adolescents and adults have a more benign course. The vast majority of older patients have an isolated CTS membrane that could easily be removed by simple surgery. If the anomaly is not recognized, however, the clinical presentation may indeed appear much more sinister than its underlying cause.

\section{References}

1. Said SM, Ibrahimiye AN, Punn R, Hanley FL. Hemoptysis as a rare presentation of cor triatriatum sinister. J Thorac Cardiovasc Surg. 2015;150:e73-5.

2. Saxena P, Burkhart HM, Schaff HV, Daly R, Joyce LD, Dearani JA. Surgical repair of cor triatriatum sinister: the Mayo clinic 50-year experience. Ann Thorac Surg. 2014;97:1659-63.
3. Alphonso N, Nørgaard MA, Newcomb A, d'Udekem Y, Brizard CP, Cochrane A. Cor triatriatum: presentation, diagnosis and long-term surgical results. Ann Thorac Surg. 2005;80:1666-71.

4. Yaroglu Kazanci S, Emani S, McElhinney DB. Outcome after repair of cor triatriatum. Am J Cardiol. 2012;109:412-6.

5. Zepeda IA, Morcos P, Castellanos LR. Cor triatriatum sinister identified after new onset atrial fibrillation in an elderly man. Case Rep Med. 2014;2014:674018.

6. Bezgin T, Canga Y, Karagöz A, Yilmaz F, Doğan C, Elveran A, et al. Multimodality imaging of cor triatriatum sinister in octogenarian. Echocardiography. 2014;31:E254-6.

7. Eichholz JL, Hodroge SS, Crook JJ, Mack JW Jr, Wortham DC. Cor triatriatum sinister in a 43-year-old man with syncope. Tex Heart Inst J. 2013;40:602-5.

8. Tachibana K, Takagi N, Osawa H, Takamuro M, Yokozawa M, Tomita H, et al. Cor triatriatum and total anomalous pulmonary venous connection to the coronary sinus. J Thorac Cardiovasc Surg. 2007;134:1067-9.

9. Konstantinov I, Yun TJ, Caldarone C, Coles JG. Supramitral obstruction of left ventricular inflow tract by supramitral ring. Oper Tech Thorac Cardiovasc Surg. 2004;9:247-51.

10. Huhta JC, Edwards WD, Danielson GK. Supravalvular mitral ridge containing the dominant left circumflex coronary artery. J Thorac Cardiovasc Surg. 1981; 65:577-9.

11. Lam CR, Green E, Drake E. Diagnosis and surgical correction of 2 types of triatrial heart. Surgery. 1962;51:127-37. 